\title{
Flexibilidade e crise do emprego industrial - sindicatos, regióes e novas ações empresariais
}

JOSÉ RICARDO RAMALHO"

\section{Resumo}

Flexibilidade é uma palavra chave que sintetiza as mudanças decorrentes da reestruturação pelas quais passou a indústria nas últimas décadas. A redução do emprego industrial e suas consequências sociais e econômicas, são o foco da crítica social dirigida aos projetos baseados no padrão flexível, exigindo cada vez mais das empresas a elaboração de argumentos e ações para justificar e legitimar essa nova faceta do processo produtivo.

O projeto AutoVision da montadora multinacional de veículos Volkswagen, aplicado em duas regiões - Wolfsburg, na Alemanha e ABC paulista, no Brasil, chama a atenção pelas características de uma intervenção social que veio acompanhada de um discurso mais elaborado de justificação. A hipótese a ser testada é a de que as iniciativas mais recentes das empresas globalizadas com base na flexibilidade, apontam para um protagonismo político na formulação de propostas com o objetivo de minorar os efeitos da redução do emprego na indústria e para a construção de uma retórica que naturaliza o emprego flexível. Teoricamente, esse caso permite também discutir os diferentes arranjos sociais com base na flexibilidade, que são criados regionalmente pelas empresas multinacionais e os modos como estas justificam suas ações ${ }^{1}$.

Palavras-chave: Flexibilidade. Reestruturação produtiva. Empresas globais. Relações de trabalho.

Nota: este artigo sofreu alterações por solicitação do editor em 2011, conforme ERRATA publicada no Volume 13 Número 27 do periódico.

\footnotetext{
* Doutor em Ciência Política pela USP; Professor Titular do Departamento de Sociologia e do Programa de Pós-graduação em Sociologia e Antropologia da UFRJ.

1 Este texto foi escrito a partir de pesquisa de campo realizada em Wolfsburg e Salzgitter, na Alemanha, em abril de 2007, e do diálogo permanente com os colegas do WZB - Wissenschaftszentrum Berlin für Sozialforschung, em Berlim, instituição que me acolheu durante esse período, na qualidade de pesquisador-visitante. No WZB, meu especial agradecimento vai para o Professor Ulrich Jürguens, pelo convite e pelo diálogo acadêmico, assim como para sua equipe, em especial Antje Bloecker. Sou grato também a Flavio Benites, em Wolfsburg, e Eva Lavon, em Salzgitter, por terem viabilizado a realização de entrevistas
} 


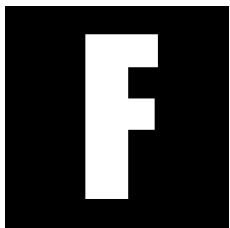

lexibilidade é uma palavra-chave que sintetiza as mudanças decorrentes da reestruturação pelas quais passou a indústria nas últimas décadas. A estratégia de flexibilizar relações para dentro e para fora das firmas transformou-se na característica mais importante da nova lógica empresarial, ao mesmo tempo em que as novas práticas tiveram grande impacto sobre trabalhadores e localidades. A redução do emprego industrial e suas consequências sociais e econômicas, são o foco da crítica social dirigida aos projetos baseados no padrão flexível, exigindo cada vez mais das empresas a elaboração de argumentos e ações para justificar e legitimar essa nova faceta do processo produtivo.

A partir desse raciocínio, o projeto da montadora multinacional de veículos Volkswagen (doravante VW), aplicado em duas regiões onde sua presença econômica e política é significativa- Wolfsburg, na Alemanha e ABC paulista, no Brasil, chama a atenção pelas características de uma intervenção social que veio acompanhada de um discurso mais elaborado de justificação. Com vistas a minorar os efeitos sociais do corte de pessoal nas fábricas e com a implantação de estratégias mais flexíveis de recrutamento e relacionamento com os trabalhadores, o projeto AutoVision foi apresentado inicialmente como um conceito (1997) que se concretizou com a criação da empresa Wolfsburg AG, uma parceria público-privada entre a VW e a municipalidade alemã, e da AutoVision $\mathrm{GmbH}$, uma empresa subsidiária da VW para atuar como agência de serviços para a sua cadeia produtiva. Desde o início, a ideia do projeto era tentar equacionar em novas bases o problema do desemprego causado pela reestruturação industrial e estimular as atividades para as quais a cidade pudesse se re-vocacionar e criar novos postos de trabalho. Com a intenção de repetir a experiência em outras

com trabalhadores e assessores; e no Brasil, a Wagner Santana e Zeira Camargo, pelos contatos em Wolfsburg; e Neide Esterci pela leitura e sugestões ao texto. Minha gratidão principal vai para Luiz Ramalho e Barbara Staib em Berlim, pela acolhida calorosa e pelo apoio logístico sem os quais esse trabalho não teria se realizado. Além do material recolhido na Alemanha, os dados, informações e entrevistas que sustentam o texto são também resultados parciais de projetos de pesquisa em andamento apoiados pelo Conselho Nacional de Desenvolvimento Científico e Tecnológico - CNPq e pela Fundação de Amparo à Pesquisa do Estado do Rio de Janeiro - FAPERJ (Programa Cientistas do Nosso Estado), instituições que permitiram essa estadia no exterior e às quais também sou grato. 
localidades, no entanto, o anúncio do projeto da Auto Visão Brasil para o ABC, em 2003, não teve o mesmo impacto de sua contra-face alemã: surgiu em um momento de conflito trabalhista e teve baixo impacto regional.

O projeto AutoVision permite mostrar também que os princípios da flexibilidade tornaram-se prática comum e foram incorporados às novas formas de emprego, apesar das resistências interpostas por trabalhadores e sindicatos, do seu elevado custo social para localidades ${ }^{2}$ e regiões, e mais, dos constrangimentos associados a compromissos de responsabilidade social. A hipótese a ser testada é a de que as iniciativas mais recentes das empresas globalizadas com base na flexibilidade, apontam para um protagonismo político na formulação de propostas, com o objetivo de minorar os efeitos da redução do emprego na indústria e para a construção de uma retórica que naturaliza o emprego flexível. Nesse contexto, embora os sindicatos, os trabalhadores e as localidades não sejam passivos, suas ações são confrontadas pela força do novo discurso de justificação que tem a marca dos novos preceitos da responsabilidade social corporativa.

Teoricamente, esse caso contribui para o debate sobre os argumentos e os efeitos práticos da flexibilidade que, como estratégia empresarial a partir dos anos 1970, colocou os assalariados sob "o peso da incerteza do mercado" ${ }^{\prime 3}$. Permite também discutir os diferentes arranjos sociais, com base na flexibilidade, que são criados regionalmente pelas empresas multinacionais e os modos como estas justificam suas ações que têm

2 Parte-se de uma concepção de localidade que, como diz Cooke (1989, p. 296), não pode ser vista apenas como mera receptora de algo decidido em processos nacionais e internacionais, mas que está ativamente envolvida na sua transformação, mesmo que não tenha controle total sobre seu próprio destino. As localidades não seriam apenas lugares ou mesmo comunidades. Elas seriam a soma de energia social e agência, e o resultado da aglomeração de diversos indivíduos, grupos ou interesses sociais no espaço, não seriam passivas ou residuais mas, de vários modos e graus, centros de consciência coletiva.

3 Para Boltanski e Chiapello (1999, p. 292) a flexibilidade pode ser decomposta em uma flexibilidade interna, que se baseia na transformação profunda da organização do trabalho e das técnicas utilizadas (polivalência, auto-controle, desenvolvimento da autonomia etc) e em uma flexibilidade externa que supõe uma organização do trabalho dito em rede, dentro da qual as empresas "enxutas" encontram os recursos que lhes faltam com o uso intenso da 
como objetivo produzir bons resultados econômicos e dividendos para donos e acionistas, em contextos onde há, da parte das sociedades locais, expectativas de um compromisso social da empresa com o bem-estar de seus habitantes e com a sustentabilidade do desenvolvimento econômico projetado. A proposta do texto é: a) identificar os mecanismos que constroem essa justificação a partir da perspectiva de que o espírito do capitalismo tem duas faces: uma voltada para a acumulação de capital e outra, para princípios de legitimação (cf. BOLTANSKI; CHIAPELLO, 1999); e b) compreender as estratégias que são acionadas sob o nome genérico de responsabilidade social corporativa. Segundo Kinderman (2007, p. 2-3), esta responsabilidade, entendida como o engajamento das empresas em questões sociais e ambientais, re-emergiu como base retórica dominante para a legitimação do capitalismo contemporâneo. E "é potencialmente um conceito hegemônico porque ajuda a assegurar a reputação das firmas, ao mesmo tempo em que preenche importantes requisitos funcionais do sistema econômico nos níveis local, regional e global, além de ser maleável o suficiente para acomodar os críticos do status quo".

Crise do emprego e das regiões industriais

Empresas do setor automotivo, principalmente montadoras como a VW, são globalizadas e estruturadas em redes e, premidas por uma grande competição, impõem cada vez mais sua intenção de reduzir os custos do trabalho, ora enxugando pessoal, ora flexibilizando relações e acordos trabalhistas - estabelecidos de forma estável e historicamente consistentes como no caso alemão, ou de modo mais passageiro e dependente do poder de barganha, de sindicatos territorializados, como no caso brasileiro ${ }^{4}$.

Mas a questão do emprego vai além do embate entre capital e trabalho dentro da fábrica. A reestruturação afetou também a situação social

subcontratação, mão de obra maleável em termos de emprego (emprego precário, por tempo determinado etc) e jornadas de trabalho com horários variáveis.

4 No capítulo do seu livro Sociedade em Rede, voltado para a questão do trabalho nesse novo 
de regiões que tiveram suas histórias associadas à industrialização. Alemanha e Brasil sofreram as mudanças de modo diferenciado: no país sede da VW, o deslocamento da produção para outras localidades, principalmente do Leste Europeu, representou uma ameaça aos acordos coletivos assinados com os sindicatos que estabeleciam segurança no emprego, e uma ameaça para Wolfsburg que entrou em crise com a redução dos postos de trabalho. No Brasil, o deslocamento ocorreu através de políticas industriais de re-espacialização internas ao país, promovidas pelo Governo Federal que, ao longo dos anos 1990, modificou a geografia da indústria automotiva ao incentivar novos municípios a oferecerem vantagens fiscais às empresas, abrindo-Ihes a possibilidade de buscar localidades com baixa atividade sindical. Essa mobilidade induzida colocou em crise também o ABC paulista, região na qual a VW desempenha um papel econômico bastante ativo (Cf. RODRIGUES; RAMALHO, 2007).

A crise dessas localidades/regiões colocou em alerta administrações públicas, políticos, entidades da sociedade civil, pequenos e médios empresários, enfim todos aqueles de alguma forma relacionados ao ambiente econômico local. Os problemas causados pelos processos de flexibilidade sobre as localidades passaram a fazer parte de uma pauta admitida pelas empresas sob a rubrica da responsabilidade social corporativa. O exemplo em discussão revela que, tanto em Wolfsburg, como no $\mathrm{ABC}$ paulista, as consequências do desemprego geraram grandes preocupações, mas os resultados até agora obtidos pela intervenção da VW demonstram que a eficácia do projeto "AutoVision" pode variar conforme as raízes ou os compromissos da empresa assumidos historicamente com seus operários, regiões ou países.

momento do capitalismo, Castells identifica o aumento extraordinário de flexibilidade e adaptabilidade possibilitadas pelas novas tecnologias que contrapõem a rigidez do trabalho à mobilidade do capital. E reconhece uma pressão contínua do sistema para tornar a contribuição do trabalho o mais flexível possível. "A produtividade e a lucratividade foram aumentadas, mas os trabalhadores 
O poder de reação dos organismos de representação dos trabalhadores parece reduzido nesse contexto, pressionados pela ameaça constante de que as empresas possam deslocar partes importantes do processo produtivo para diferentes lugares do planeta. Os salários mais baixos nos países emergentes, por exemplo, acabam servindo como um instrumento dos empregadores nos processos de negociação com os trabalhadores dos países com sindicalismo estruturado, como é o caso alemão. As negociações têm resultado mais em medidas de preservação do emprego do que em greves ou conflitos. A estratégia de os sindicatos se articularem em rede é uma alternativa que tem gerado alguns resultados positivos, na medida em que, no caso da VW, consegue intervir em conflitos em que a empresa se envolve em diferentes localidades. O Comitê Mundial de Comissões de Fábrica do Grupo VW, criado em 1998, foi, sem dúvida, uma reação pró-ativa ao processo de globalização, abrindo a possibilidade de construir novas pautas e discutir novas estratégias ${ }^{5}$.

Na Alemanha, o combate ao desemprego assumiu preponderância no discurso da responsabilidade social corporativa da VW, agora não simplesmente como filantropia, mas com propostas de participação direta da empresa no projeto de criação de postos de trabalho (flexíveis). Isto se deu através de iniciativas da própria empresa, diante da crise social na localidade onde se encontrava sua principal unidade produtiva, Wolfsburg, na Alemanha. No Brasil, os mecanismos utilizados pela indústria automotiva nos anos 1990 (inclusive a VW) para implementar uma organização produtiva flexível, pela própria especificidade da regulação trabalhista e

perderam proteção institucional e ficaram cada vez mais dependentes das condições individuais de negociação e de um mercado de trabalho em mudança constante" (1998, p. 298-299).

5 Segundo Shulten (1998), relatando para a EIROnline, em maio de 1998, a direção da empresa de automóveis alemã Volkswagen (VW) e seu organismo europeu de Comissões de Fábrica anunciaram a fundação do "Conselho Mundial de Comissões de Fábrica do Grupo VW" (VW-Weltbetriebsrat). De acordo com a declaração conjunta da direção do grupo VW e a Comitê Europeu de Comissões de Fábrica da VW, o novo Comitê Mundial será composto por 
da política de incentivos fiscais estabelecidas pelo Governo Federal nesse período, foram muito mais no sentido de buscar novos territórios produtivos com baixos salários e pouca presença sindical. Quando anunciado no Brasil, o projeto 'AutoVision' apresentava as mesmas ideias da experiência alemã, no entanto, o contexto trabalhista e os recursos aplicados pela VW na Auto Visão Brasil, geraram resultados pífios no ABC paulista, demonstrando que a empresa assumia compromissos diferentes conforme os diversos países em que atuava.

Entre as justificativas da empresa-montadora-multinacional, para o seu empenho a fim de reduzir os efeitos do desemprego industrial, destacam-se os laços ou os compromissos (ou o enraizamento) da empresa com a localidade/região. O projeto AutoVision, na Alemanha, é paradigmático. Em Wolfsburg, onde a experiência foi inicialmente implantada, havia razões nacionais e regionais para uma enorme pressão social contra o corte de empregos e, para uma crítica à empresa, como responsável direta por essa crise social. Entre essas razões estava o fato de que a região/ estado da Baixa Saxônia detinha um conjunto significativo de ações da VW o que lhe dava poderes para exigir como condição para a implementação da flexibilidade, a criação de novos postos de trabalho. A crise do emprego talvez tenha significado uma oportunidade para que a empresa experimentasse um outro tipo de relação com a localidade conferindoIhe, em princípio, um papel menos coadjuvante. A cidade foi convocada (pela empresa) a participar do processo de sua transformação, através da criação da Wolfsburg AG, uma parceria entre a VW e a Municipalidade. Novos investimentos foram concretizados, e a face da cidade mudou um pouco ao sabor das novas estratégias empresariais. No ABC paulista, a implantação do projeto "AutoVision" não demonstrou ter o mesmo compromisso com os trabalhadores e com a região. 


\section{Mudanças nas relações de trabalho na Alemanha}

Nas últimas décadas, a mudança nas relações de emprego afetou de modo distinto os dois países. Isso não quer dizer que as coordenadas gerais das empresas globais não se confirmassem - flexibilidade na produção e sindicatos na defensiva - no entanto, o timing foi diferente e teve relação direta com o acúmulo de força política adquirida em contextos diversos.

Na Alemanha, o modelo de relações de trabalho passou, nos últimos anos, por uma substantiva transformação que incluiu a parceria entre capital e trabalho simbolizado pelo sistema de co-determinação, um padrão de emprego de longo prazo para muitos empregados, uma ênfase na qualificação e, consequentemente, na formação profissional, uma competição baseada na produção de qualidade. (Cf. JÜRGENS et al, 2006, p. 3). Para os sindicatos, a questão principal foi a de combinar a flexibilidade com uma característica do modelo alemão, a proteção do emprego.

A indústria automotiva faz parte do principal núcleo industrial da Alemanha. É uma das maiores empregadoras e tem sido uma das "máquinas de crescimento" da economia alemã nos últimos anos (responsável por cerca de $12 \%$ do emprego, $20 \%$ dos investimentos no setor industrial alemão e 23\% das exportações). É nesse setor industrial que os sindicatos têm uma base tradicional de apoio e o padrão de relação industrial tem uma enorme influência em toda a indústria e no processo de regulamentação do emprego. Em 2004, o nível de sindicalização na indústria automotiva estava em $75 \%$, contra $30 \%$ na economia como um todo (EIROnline, 1, 2004: VI), e em todas as montadoras havia comissões de fábrica (works councils) organizadas. (Cf. JÜRGENS et al, 2006, p. 20). A garantia da segurança no emprego sempre foi elevada, com um claro compromisso das comissões de fábrica e dos sindicatos de proteger o emprego. Nos anos 1980, iniciou-se uma luta pela redução do tempo de trabalho semanal que culminou com um acordo histórico da VW para 
a redução da jornada para 28.8 horas. (JÜRGENS et al, 2005, p. 14-15; HAIPETER, 2000; PROMBERGER; ROSDÜCHER; SEIFERT, 1996, citados por JÜRGENS et al, 2005).

Esta situação sofreu alterações a partir dos anos 2000, e a redução do tempo de trabalho começou a ser vista como colocando em risco a segurança do emprego, sendo a extensão do tempo de trabalho propagada como um passo necessário para se retomar o crescimento do emprego e da competitividade. Nesse contexto, segundo o EIROnline (cf. 1, 2004: V), o poder de barganha das montadoras no campo da política salarial e de emprego cresceu enormemente. Com base nos custos do trabalho, nos sistemas de regulação do emprego e nos níveis de produtividade calculados a partir de comparações internacionais, as empresas passaram a usar a ameaça de mudança das unidades produtivas para países com baixos salários. O resultado foi a construção de novos acordos dentro da indústria automobilística alemã, forçando as comissões de fábrica a aceitarem uma redução de 2,79\% nos salários básicos de todos os empregados.

Outro fator foi o uso crescente de trabalhadores recrutados em agências de serviços pessoais (agency workers). O caso da AutoVision $\mathrm{GmbH}$, subsidiária da VW, serve como um exemplo dessa nova tendência, já que foi criada em 2001 para "tratar de pessoal" e oferecer um serviço de agenciamento de emprego flexível, emprestando trabalhadores da agência para a própria empresa (VW) ou para outras empresas na Alemanha, com salários 10 a $12 \%$ mais baixos do que os trabalhadores "essenciais" da VW.

De acordo com Jürgens et al (2005, p. 17-18 e 2006, p. 26-28), outra questão importante nesse processo é a crescente segmentação das condições de emprego entre e dentro das empresas. Segundo os autores, tomando a VW como exemplo, é possível distinguir diferentes status nas posições de emprego: trabalhadores essenciais (com tempo médio de trabalho de 28.8 horas semanais), recém contratados pela VW com entrada 
em 2005, e com a mesma proteção dos trabalhadores essenciais, porém, os salários mensais estão, em media, 8\% mais baixos, com tempo de trabalho de 35 horas semanais, o que significa salários $24 \%$ menores; empregados com contratos por tempo determinado e empregados da AutoVision $\mathrm{GmbH}$, sem proteção no emprego, salários mais baixos e jornada de 35 horas semanais - empregados da agência de serviços pessoais na VW, mas que trabalham na Wolfsburg AG, agência de colocação de desempregados, dirigida pela VW e pela cidade de Wolfsburg, com hora de trabalho em media 40\% mais baixa do que a dos trabalhadores essenciais da VW.

Também nos acordos mais recentes, a ameaça de transferir empregos forçou os sindicatos a trocar a garantia de emprego pela flexibilização dos salários e das condições de trabalho. Em texto produzido para a ElROnline, Dribbusch (2004) relata e comenta um acordo de 2004 entre a VW e os sindicatos onde esse tipo de concessão se realizou. Segundo ele,

o compromisso (...) inclui um conjunto de concessões feitas pelo sindicato IG Metall, em particular um congelamento de salários até 2007, e em troca de um compromisso da empresa de salvaguardar o emprego até 2011 e fazer novos investimentos para assegurar o futuro das fábricas alemãs. (...) Tinha ficado claro desde o início das negociações que, confrontados com a ameaça de realocar a produção para outros países, que o IG Metall iria priorizar a salvaguarda do atual nível de emprego sobre os aumentos salariais. No entanto, as concessões foram consideráveis, incluindo em particular a aceitação de um futuro sistema de pagamento em dois níveis o que se choca com princípios tradicionais do sindicalismo.

\section{A reestruturação na VW e o projeto AutoVision}

A VW é uma das maiores montadoras de veículos do mundo. Suas fábricas estão espalhadas por vários países e, em alguns casos como o do 
Brasil, sua influência tem sido decisiva no processo de industrialização e de formação de um mercado de trabalho especializado.

A reestruturação a que foram obrigadas a fazer as empresas da indústria automotiva diante das novas exigências de produtividade do mercado mundial, levou a VW a um movimento duplo de redefinição de suas fábricas antigas e à aplicação de novos investimentos em fábricas cada vez mais enxutas e flexíveis em termos de relações de trabalho. As estratégias variaram, mas os objetivos principais foram atingidos, tanto na Alemanha como no Brasil. O surgimento da Auto $5000^{6}$, uma montadora criada dentro de sua própria fábrica de Wolfsburg, cujos trabalhadores tiveram seus salários negociados em bases inferiores, confirma esse processo, assim como a fábrica de Resende no Estado do Rio de Janeiro, que implantou o "consórcio modular", estrutura na qual a VW mantém o controle do processo produtivo, mas não executa mais a função de montagem que, sob o mesmo teto, fica sob a responsabilidade de um conjunto de outras empresas "parceiras" (Cf. ABREU; BEYNON; RAMALHO, 2000; RAMALHO; SANTANA, 2006). Em ambos os casos, as fábricas enxutas rompem com práticas salariais e sindicais anteriores e colocam os trabalhadores das fábricas reestruturadas em uma situação mais frágil em termos da manutenção de acordos salariais anteriores e em termos da segurança no emprego.

O projeto 'AutoVision' tem a cidade-sede da VW como o centro da experiência na qual emprego e flexibilidade caminharam juntos. A VW nasceu ligada a essa localidade da Baixa Saxônia, na Alemanha que,

membros do Comitê Europeu de Comissões de Fábrica e representantes das fábricas da VW na África do Sul, América e Ásia.

6 Segundo o Relatório Anual da VW de 2002, intitulado From employee to co-operator - Auto $5000 \mathrm{GmbH}$ and the future of industrial labour in Germany, a ideia da criação da Auto 5000 veio dos próprios empregados. De acordo com esse documento, as fábricas alemãs não tinham condição de competir em termos de custos com fábricas de outros países. "Quando em 1999, a produção do Colorado (um veículo off-road) passou ao largo das fábricas alemãs e foi para Bratislava, na Eslováquia, os representantes dos trabalhadores na comissão de fábrica exigiram 
depois da II Guerra, recebeu o nome de Wolfsburg. A instalação da fábrica esteve associada ao contexto político do nazismo, inclusive com a produção de armamentos e o uso de trabalho forçado, mas, depois de recuperada pelos britânicos para a fabricação de automóveis e repassada para o governo local no final dos anos 1940, a VW já detinha 50\% do mercado de veículos e empregava quase 10 mil pessoas $^{7}$.

Os vínculos atuais entre a empresa e a cidade de Wolfsburg permanecem intensos. Quem chega de trem para uma visita (como foi o meu caso) ${ }^{8}$, já na estação ferroviária, percebe que a fábrica da Volkswagen (anunciada como a maior fábrica de automóveis do mundo na atualidade) ocupa um espaço físico e simbólico proeminente sobre a localidade. Embora a visita às instalações fabris tenha revelado uma produção com tecnologia atualizada com, por exemplo, o uso disseminado de robôs, o que chama a atenção para quem olha a fábrica de fora é a presença de quatro gigantescas chaminés de tijolo vermelho, no estilo da primeira revolução industrial, que compõem uma das usinas de força do complexo fabril. Na parede externa de uma delas, está fixado um inconfundível e gigantesco escudo com as iniciais VW. A fábrica tem quilômetros de extensão e possui cerca de 46 mil trabalhadores. A separação física entre a cidade e a empresa fica nítida pela presença de um grande canal que cria uma barreira natural entre a área urbana de comércio e moradias e o espaço dedicado apenas à produção industrial.

Ao circular pela cidade pode-se notar a existência de construções novas, algumas delas com grande arrojo arquitetônico. O próprio prédio do sindicato (IG Metall), confirma a primeira impressão de uma injeção recente de recursos. Wolfsburg ainda é uma company town, com uma história associada à fábrica. A força da VW permanece visível e preponderante nos destinos da localidade e da região.

um acordo para que os futuros investimentos ocorressem em localidades na Alemanha" (p. 40). Sobre este assunto ver Schumann; Kuhlmann; Sanders; Sperling, 2005. 
O projeto 'AutoVision' partiu da empresa, como uma resposta aos cortes dos postos de trabalho considerados "excedentes" pela dinâmica da produção automotiva e que tornaram a questão do desemprego tema de preocupação central da cidade e de seus habitantes, sem falar do sindicato e da comissão de fábrica. Nas palavras de um assessor do IG Metall, entrevistado por mim, foi um presente que a VW resolveu dar à cidade como forma de comemorar seus 60 anos em 1997. O fato é que houve de 1997 a 2000 uma grande inversão de recursos na tentativa de vocacionar a cidade para outras atividades e áreas de interesse (para além da óbvia marca de cidade industrial), que fossem criadoras de emprego e que propiciassem lazer para os de fora e trabalho para os de dentro.

As atrações impressionam o visitante pela originalidade e gigantismo dos prédios, pela criatividade turística e educacional, embora estes projetos não aparentem ter a participação da cidade e dos seus moradores. O projeto AutoVision concretizado através da Wolfsburg AG, tinha entre seus planos a atração de pessoas em busca de um lazer diferente que combinasse os confortos habituais (parque aquático, bons hotéis e restaurantes etc) com novidades que iriam desde museu de arte moderna, planetário, estádio de futebol e um prédio para atividades educacionais voltadas para a ciência; até o majestoso prédio do Autostadt, posicionado junto à fábrica com o objetivo de associar o tema automóvel a um conjunto de atividades culturais. A inovação dessa iniciativa se estende até mesmo para o processo de compra do veículo. Ao lado de duas grandes torres de vidro, vitrines nas quais se expõem os carros, o potencial comprador é introduzido a uma moderna construção de aço e ferro onde pode experimentar o automóvel, fazer o negócio e assisti-lo descer por um elevador existente dentro das torres até chegar ao destino final. Nesse ambiente, enquanto espera, o comprador pode visitar o complexo de atrações do Autostadt dentre as quais se destaca um conjunto de peque- 
nos prédios como se fosse um museu do automóvel, mas que apresenta também os novos modelos e suas performances. Em resumo, o poder de transformação da cidade encontra-se nas mãos e nas ideias da VW e sua reconfiguração atual revela mais do que nunca a intenção de imprimir uma nova marca nesse relacionamento, indicando que a criação de novos empregos exigiria criatividade, flexibilidade e colaboração, inclusive no que diz respeito a novas formas de trabalho.

\section{A VW, o desemprego e a responsabilidade social corporativa}

Na Alemanha, a pressão das empresas por uma flexibilização das regras trabalhistas veio acompanhada de um discurso sobre a necessidade de abordar a questão do desemprego de "forma criativa" e como parte da responsabilidade social corporativa ${ }^{9}$. Diante dessas novas ideias e propostas, os sindicatos foram postos na defensiva.

O debate sobre responsabilidade social corporativa (RSC) ganhou um novo impulso na Comunidade Europeia, a partir dos anos 2000. Bronchain (2003, p. 7), em trabalho organizado para a European Foundation for the Improvement of Living and Working Conditions, reproduz documento no qual ficaram definidas quais seriam as características de uma empresa com responsabilidade social: suas iniciativas devem ocorrer

7 Resumo histórico apresentado pela Volkswagen Communications, 2001.

8 Trabalho de campo realizado no mês de abril de 2007 com o apoio do WZB - Berlin.

9 Para Boltanski e Chiapello, assim como o espírito do capitalismo apresenta duas faces, uma voltada para a acumulação de capital e outra para os princípios de legitimação, a literatura gerencial pode também ser lida em dois planos diferentes: um técnico, com receitas práticas para melhorar o rendimento das organizações, mas ao mesmo tempo uma face com forte tonalidade moral. A orientação não é constitutiva mas prescritiva. Essa literatura seleciona o caso conforme sua capacidade de demonstração - o que deve ser feito versus o que não deve - e só retém da realidade os aspectos que estão adequados à orientação do que interessa impulsionar. "A literatura gerencial não pode estar orientada unicamente para a busca do lucro. Ela deve igualmente justificar o modo como o lucro é obtido, dar aos quadros os argumentos 
de modo voluntário, i.é. indo além dos requisitos convencionais ou da regulação existente; deve estar em interação com os stakeholders; deve ter preocupações sociais e ambientais integradas nas operações empresariais.

Como a ação das empresas afeta um conjunto grande de agentes sociais, a discussão sobre RSC trata também do impacto das atividades empresariais sobre as localidades. De acordo com Bronchain (2003, p. 9-10 e p. 14),

isto se dá basicamente em termos do emprego de pessoas e da produção de bens e serviços, que pode envolver fornecedores e consumidores locais. Contudo, para o autor, as questões mais desafiadoras para a empresa vis-à-vis, a comunidade local são a identificação dos stakeholders (...), definindo suas expectativas e arrumando espaço para que eles atuem.

Um exame dos relatórios expedidos pela VW, nos últimos anos, revela a preocupação da empresa em integrar às metas produtivas, um discurso voltado para as questões do desenvolvimento sustentável, tanto em termos ambientais como em termos sociais. Um exemplo é a Carta Social da VW $(2002)^{10}$ na qual empresa e trabalhadores concordam com certos princípios básicos aplicáveis no contexto de uma política corporativa em qualquer lugar do mundo. Esta Carta pode ser vista como uma resposta às críticas e pressões por parte de trabalhadores e sindicatos, mas também como parte de uma estratégia empresarial para associar ao novo padrão de flexibilidade, uma imagem de forte preocupação social.

para resistir às críticas, e para responder às exigências de justificação que lhes serão exigidas, face aos seus subordinados e em outras arenas sociais dos quais participam" (1999, p. 94-95). 10 Declaração sobre direitos sociais e relações industriais na Volkswagen (Declaration on Social Rights and Industrial Relationships at Volkswagen) (trechos traduzidos por mim):

$\S 1$ - Objetivos básicos

1.1. Liberdade de associação - Reconhece-se o direito básico de todos os empregados de criar ou se filiar a sindicatos ou representações de empregados. (...).

1.2. Sem Discriminação - Fica assegurado um tratamento e oportunidades iguais a todos, sem distinção de raça, cor da pele, sexo, religião, cidadania, orientação sexual, origem social ou crença política (...).

1.3. Livre Escolha de Emprego - A Volkswagen rejeita qualquer forma conhecida de uso de trabalho forçado. 
Em relatório de 2002 (2002, p. 13-15), a empresa afirma que a globalização é um fator decisivo para assegurar competitividade internacional e, para ser corporativamente responsável e moderna, propõe-se a tarefa de moldar a globalização para ser compatível em termos sociais e ambientais. Isto significa que o processo de globalização dos negócios deveria oferecer às pessoas de países em desenvolvimento, perspectivas futuras, assim como segurança econômica e social. Globalização não pode ser baseada em exploração. No discurso da VW, uma empresa atua socialmente (...) quando envolve seus empregados na construção do futuro, quando os apóia no desenvolvimento de sua própria empregabilidade e depois thes oferece emprego.

No Relatório sobre Desenvolvimento Sustentável 2005/2006 (2006:4), a empresa se auto-define como um global player com raízes germânicas, portanto reconhece raízes e atribui importância a elas. E avança, no discurso, ao dizer que o Grupo VW vê a responsabilidade social como algo que não se restringe ao patrocínio ou o financiamento de medidas de bem estar:

no nosso ponto de vista uma empresa só demonstra responsabilidade se atua para salvaguardar postos de trabalho, treinar seus empregados, e envolvê-los na construção do futuro corporativo", e que "diante de um contexto de dificuldade no ambiente econômico no nosso próprio mercado interno, para o Grupo VW, a responsabilidade social significa fortalecer as regiões nas quais somos ativos (...). (Idem:8 e 43)

\section{O projeto AutoVision e a Wolfsburg AG- implantação e performance}

As definições e propostas da VW, através do projeto AutoVision de 1997, concretizados na Wolfsburg AG em 1999, estão presentes em documentos disponibilizados pela própria empresa e anunciam o projeto de intervenção como um modelo a ser reproduzido em outros lugares. 
Peter Hartz, gerente de recursos humanos da VW à época, foi um dos principais formuladores do projeto. Em um de seus textos (2001), enumera o conjunto de ideias norteadoras do projeto AutoVision e afirma que sua implementação poderia ser vista como uma resposta concreta à redução dos postos de trabalho, trazida pela reestruturação industrial. O objetivo imediato era reduzir o desemprego pela metade, na cidade sede Wolfsburg, através de um caminho auto-sustentado para além da simples busca de subvenções públicas para o mercado de trabalho e de caricaturas de obras de assistência privada. Para ele, esse caminho ganhou corpo com a Wolfsburg AG, como parceria entre o município de Wolfsburg e a VW, que contou, em sua elaboração, com a participação da Comissão de Fábrica da VW e do sindicato dos metalúrgicos IG Metall. Todos os tomadores de decisão da região foram convidados a assumir responsabilidade na composição do Conselho de Administração da nova empresa, que se estruturou em quatro áreas de negócios: Assentamento de Fornecedores, Campus de Inovações, Mundo da Convivência e Agência de Serviços de Pessoal ${ }^{11}$.

O princípio por trás da Wolfsburg AG é o de (...)fortalecer a eficiência econômica de Wolfsburg a longo prazo, criando novas oportunidades de emprego. (...) Apoiamos o desenvolvimento de estruturas novas, viáveis e acima de tudo sustentáveis para a cidade e a região. Estamos fazendo isso porque sabemos o quão importante é reunir e integrar interesses e atividades econômicas, sociais e do mercado de trabalho.(...). A Wolfsburg AG é a força motora por trás da implementação bem sucedida da AutoVision em Wolfsburg. Nos colocamos a tarefa de desenvolver uma economia viável e que se auto-propaga. Dessa forma, não buscamos uma política de desenvolvimento econômico que se utiliza de

1.4. Contra o Trabalho Infantil (...).

Bratislava, 6 de Junho de 2002.

11 No levantamento realizado sob o patrocínio da Comunidade Europeia e articulado pelos European Trade Union Confederation; Union of Industrial and Employers' Confederations of Europe; European Centre of Enterprises (cf. Danau et al, 2000), o projeto AutoVision aparece como 
subsídios para criar demanda artificial, mas focamos nossas energias na criação e no desenvolvimento de negócios voltados para o futuro. (Wolfsburg AG - A vision with definite prospects. http://www.wolfsburg-ag.com).

A especificidade de Wolfsburg foi levada em consideração, contudo, somente reduzir o desemprego não pareceu suficiente para abrir novas possibilidades para a cidade. Segundo Hartz (2001), o grupo criado para reduzir o desemprego pela metade teria que se lançar na tarefa de reconhecimento de novos conceitos, novos fatos, novos modelos e novas experiências.

O fato de a cidade ser monoindustrial, ou seja, totalmente dependente da VW, e portanto, ter uma óbvia competência na produção automobilística, direcionou o projeto AutoVision para a criação de um cluster de fornecedores: $O$ assentamento de fornecedores teria que ser parte integrante do processo futuro de fornecimento, bem como do processo de seleção logística. Para Hartz, é nesse contexto que se faz a transição para a estratégia modular. $O$ assentamento no local vem ao encontro do interesse dos fornecedores porque se aproveitam da infraestrutura e agência de serviços pessoais, o que favorece a administração de custos variáveis na fase de implementação de um projeto. No processo de entrada, a maioria dos fornecedores irá recrutar novos trabaIhadores, bem como adquirir serviços adicionais na região.

Outro desdobramento importante seria, para Hartz, a instalação de um Campus de Inovações com a função de promover uma nova dinâmica do emprego:

o Campus de Inovações apóia os assentados no processo de conversão de uma boa ideia em um empreendimento bem sucedido. (...)Fazem parte da rede do Campus de Inovações: fundadores bem sucedidos, empreendedores, executivos, cientistas, técnicos especializados, conselheiros e emprestadores de capital. (HARTZ, 2001) 
Dentre as novas propostas trazidas pelo projeto AutoVision incluemse também alternativas de formação criadas para fora do mercado de trabalho industrial, mas precisamente no setor de serviços. Para Hartz (2001), na comparação internacional, empregos na área da prestação de serviços oferecem uma contribuição maior para o sucesso regional do emprego:

como parte de uma estratégia geral da formação de Cluster, este espaço assume um duplo significado: valorização das atividades que fazem parte da estrutura urbana regional e da cidade visando articular a força de consumo que hoje se escoa, bem como construir uma imagem para fora, capaz de chamar a atenção como localidade de alta qualidade de vida e símbolo da nova orientação dos cidadãos da região.

Uma novidade desse conjunto de ideias que mexeu com a questão da flexibilidade e com os acordos de trabalho tradicionalmente estabelecidos, foi a criação, nesse contexto, da AutoVison $\mathrm{GmbH}$, uma "agência de serviços pessoais", subsidiária da VW. Na argumentação de Hartz (2001), um componente sensível da redução do desemprego é uma nova forma de sociedade de trabalho a tempo parcial. Todas as novas empresas na região deveriam realizar um serviço de procurar trabalhadores, treinar, emprestar e reassumir esses mesmos trabalhadores quando estes não fossem mais necessários. Este serviço ofereceria ao desempregado a oportunidade de estabelecer relações duradouras de trabalho no longo prazo, através das possibilidades de trabalho em tempo parcial. Com este movimento circular, a agência de serviços pessoais possibilitaria reduzir a pressão dos desempregados sobre os departamentos de trabalho e tornaria possível o recrutamento de especialistas, na medida certa para a cobertura das necessidades supra-regionais.

Informações publicadas sobre essas iniciativas registram números positivos. Até o final de 2004, as atividades da Wolfsburg AG, da VW AG e da cidade de Wolfsburg tinham criado um total de 23000 empregos e somen- 
te a Wolfsburg AG fora responsável por mais de 8000. A Personal Service Agentur da AutoVision $\mathrm{GmbH}$ criou mais de 2000 empregos, o campus da inovação, cerca de 1500. A agência para a promoção de um novo conjunto de fornecedores atraiu 101 fornecedores, com cerca de 3900 empregos $^{12}$.

\section{A participação do sindicato e da comissão de fábrica}

As entrevistas que realizei com assessores do sindicato dos metalúrgicos - IG Metall - de Wolfsburg e com membro da comissão de fábrica da VW Salzgitter esclareceram a participação dos trabalhadores no projeto AutoVision ${ }^{13}$. Não foi surpresa descobrir que, embora tivessem conhecimento e preocupação com o grau de desemprego regional e tivessem participado de alguma forma na constituição do projeto, a iniciativa, os recursos e principalmente o discurso foi assumido preponderantemente pela VW. Essa "liderança" da empresa no debate sobre a questão do desemprego surgiu em um contexto em que os trabalhadores estavam na defensiva, preocupados em manter as conquistas trabalhistas anteriores, principalmente quanto ao acordo das 28,8 horas por semana. O projeto AutoVision foi criado, portanto, como uma forma de introduzir a flexibilidade "fazendo o bem", promovendo novos empregos (temporários), exercendo a função de agência de empregos (de serviços de pessoal) e serviços para dentro da própria empresa. Os trabalhadores pareciam ter perdido a força da crítica e também o discurso contra os efeitos deletérios da reestruturação, e suas ações foram mais no sentido de minorar os efeitos das novas estratégias reivindicando que a empresa, ao menos, respeitasse acordos trabalhistas consolidados.

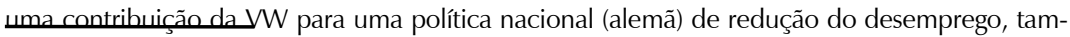
bém no sentido de dar assistência na regeneração e na diversificação da economia de Wolfsburg.

12 Disponível em: <http://www.autovision-gmbh.com>, acesso em 14 abril de 2005.

$13 \mathrm{Na}$ Alemanha, trabalhei com material impresso fornecido pelo sindicato IG Metall e realizei 
A representação operária na AutoVision $\mathrm{GmbH}$ é composta e selecionada por membros da comissão de fábrica da VW. Embora a experiência seja ainda nova e novas práticas ainda estejam em construção, já foi possível constatar que as condições salariais são piores, assim como com relação ao tempo de trabalho e à segurança no emprego.

Segundo a assessora encarregada de acompanhar o projeto AutoVision em Wolfsburg e outras localidades da Alemanha (SCHNARE, 2007), o trabalho atual do sindicato é o de buscar negociar garantias de emprego para evitar a instabilidade dos trabalhos temporários criados tanto pela AutoVision $\mathrm{GmbH}$, como pela Wolfsburg AG. Para ela, algumas conquistas pontuais foram obtidas, como um acordo negociado pela comissão de fábrica, no qual o trabalho temporário só poderia durar no máximo 3 anos, ou a empresa se obrigava a efetivar a contratação. Da mesma forma, o sindicato tem pressionado a VW no sentido de fazer passar pelo crivo da comissão de fábrica da própria VW as decisões sobre relações de trabalho da AutoVision $\mathrm{GmbH}$. Existe também uma influência do sindicato nas decisões que envolvem a Wolfsburg AG e a AutoVision GmbH. Por exemplo, a Wolfsburg AG fornece trabalhadores temporários para a AutoVision $\mathrm{GmbH}$, e o tempo de serviço do trabalhador na primeira empresa é reconhecido pela segunda.

Para um dos membros da comissão de fábrica da VW em Salzgitter (KAYS; LAVON, 2007), destacado para atuar junto à AutoVision $\mathrm{GmbH}$, a nova empresa foi pensada como uma plataforma de inovação no que diz respeito ao emprego e como forma para atrair novas fábricas para a região. O sindicato criou uma representação especialmente para os empregados da AutoVision que trabalham dentro de uma fábrica da VW. Segundo esse sindicalista, 98\% dos trabalhadores da AutoVision $\mathrm{GmbH}$ tem um vínculo direto com a produção na VW, os salários são definitivamente mais baixos, explicados pela competição que a VW tem que enfrentar no mercado. Mas, segundo ele, a comissão de fábrica prefere a produção de peças com trabalhadores 
da AutoVision $\mathrm{GmbH}$, mesmo com salários mais baixos, do que com outras empresas sobre as quais não tem controle, porque a VW tem uma filosofia que está presente na AutoVision $\mathrm{GmbH}$ e é muito melhor do que a dos fornecedores em particular ou da indústria metalúrgica em geral.

Desses relatos pode-se depreender que, para a VW, o que está em jogo não é uma mudança na sua prática de negociação com a representação dos trabalhadores, que parece ter continuado o mesmo em linhas gerais na AutoVision $\mathrm{GmbH}$, mas a introdução da flexibilidade e da possibilidade real de quebrar a rigidez dos acordos coletivos estabelecidos e fragmentar a estrutura salarial. Enquanto o sindicato e as comissões cuidam dos salários, cada vez mais baixos, a empresa está discutindo e comandando o debate sobre o formato do novo emprego dentro do espírito da responsabilidade social corporativa, fazendo uso das vantagens simbólicas que isso traz para a imagem na competição do mercado.

\section{O projeto Auto Visão no ABC paulista}

A VW é uma das empresas pioneiras da indústria automotiva no Brasil. Instalada nos anos 1950, em São Bernardo do Campo, foi parte integrante do processo de desenvolvimento industrial do país, o que incluiu não só a produção de veículos propriamente dita, como também a atração de trabalhadores e a formação de uma poderosa classe trabalhadora metalúrgica, bem como um impulso ao fortalecimento do sindicato da categoria. A ideia da Auto Visão Brasil foi introduzida em uma conjuntura de conflito entre a empresa e o sindicato em 2003, na qual estava em jogo o destino de 4000 trabalhadores considerados desnecessários pela VW no ABC e deixou a impressão de ser uma estratégia para enganar os trabalhadores, reduzir postos de trabalho e direitos. O anúncio do projeto Auto Visão foi inicialmente bem visto pelos sindicalistas brasileiros, e suas 
vantagens, a partir da experiência alemã, foram destacadas pela empresa, inclusive com uma apresentação especial dos seus objetivos para o Presidente da República ${ }^{14}$.

As palavras do presidente do Sindicato dos Metalúrgicos do $\mathrm{ABC}^{15}$ demonstram otimismo com o projeto Auto Visão, tendo em vista as necessidades de buscar alternativas à crise econômica e de emprego da região do ABC. Sua compreensão da iniciativa em Wolfsburg revela preocupação com a questão do desemprego e identifica motivações diferentes na tentativa de implantar o processo no Brasil:

Nesta crise intitulada Auto Visão, a Volkswagen cometeu um grave erro, porque ela trouxe para o Brasil um projeto que eu acho muito bem sucedido na Alemanha, que partiu da seguinte filosofia: Wolfsburg é uma cidade onde se a Volkswagen fechar ela acaba (...). A cidade acaba sendo beneficiária e vítima do que ocorre com uma empresa desse porte. A empresa que chegou a ter 70 mil trabalhadores, de repente tem 50 mil (...). O desemprego se tornava um problema, da ordem de $17 \%$ (...). Aí eles resolveram adotar um projeto que buscasse alternativas econômicas capazes de reduzir o desemprego. Então o eixo inicial não foi uma ação voltada para dentro da Volkswagen, mas foi uma ação voltada para a comunidade, onde entrou a comunidade, o poder público local e a Volkswagen. (José Lopes Feijóo, Presidente do Sindicato dos Metalúrgicos do ABC, em 18/06/2004, São Bernardo, SP).

Para Feijóo, a preocupação no Brasil parecia ser a de resolver problemas imediatos e relativos à economia interna na empresa.

duas entrevistas gravadas e uma entrevista anotada. As visitas às instalações de duas fábricas da VW me ofereceram a oportunidade de registrar impressões e fotografar seus pontos mais destacados.

14 Cleide Silva e Ari Schneider, 'A Volks não pode nem pensar em sair do País' - entrevista com Paul Fleming, presidente da VW-Brasil - ESP 10/08/2003.

15 Para obter informações sobre a VW e o ABC, foram realizadas, em 2004, em São Bernardo do Campo (SP), um conjunto de cinco entrevistas gravadas com os principais dirigentes do Sindicato dos Metalúrgicos do $\mathrm{ABC}$ à época, com destaque para o presidente do sindicato e o 
Quando eles propuseram esse projeto aqui, começaram com uma história esquisita, de que queriam dar um presente ao governo Lula, um projeto voltado para a geração de empregos, desenvolvimento de novas atividades econômicas. Só que, ao anunciar o projeto, vincularam ao fato de ter 4 mil trabalhadores excedentes em duas plantas. Então, todo mundo viu como um projeto para demitir os trabalhadores da Volkswagen. Aí fomos pro pau, pra briga, e nessa briga conseguimos um acordo importantíssimo. Não só resolveu o impasse daquele momento, como nos colocou um desafio (...) de colocar a Auto Visão no eixo, na rota correta, que é o que ela se propôs a fazer na Alemanha. (José Lopes Feijóo, Presidente do Sindicato dos Metalúrgicos do ABC, em 18/06/2004, São Bernardo, SP).

Lideranças de trabalhadores ligadas à própria $\mathrm{VW}$ no $\mathrm{ABC}$ também interpretaram dessa forma a proposta da Auto Visão no Brasil.

O que ocorreu é que esse projeto sofreu uma reviravolta, associado à situação da WW mundial, com a queda de ações nas bolsas, a pressão para a redução de custos... Então o Brasil passou a ser uma situação que precisava ser enfrentada. E a Auto Visão acabou vindo como instrumento para apoiar o redimensionamento das operações da empresa no Brasil. Portanto uma coisa voltada para dentro da VW, para dentro da corporação e com uma finalidade efetiva de redução de custos, redução da dívida que a empresa tinha com Bancos, perdendo, portanto, aquilo que seria o aspecto, digamos atrativo(...). (Mario Barbosa, ex-trabalhador da VW do Brasil, ex-membro do Comitê Mundial da VW, ex-diretor do Sindicato dos Metalúrgicos do $\mathrm{ABC}$ e coordenador do curso de Políticas Públicas do sindicato, em 04/06/2004, em São Bernardo do Campo,SP).

$\mathrm{O}$ acordo brasileiro entre a VW e o sindicato dos metalúrgicos do ABC para criar a Auto Visão Brasil aparece em um documento elaborado pelo DIEESE de São Bernardo (SP), que aponta para as dificuldades encontradas no Brasil para a implantação do projeto e descreve o formato 
final do acordo que envolveu os trabalhadores considerados excedentes pela VW do ABC.

Após uma série de difíceis negociações, empresa e sindicato chegaram a um termo de acordo que divide o Projeto Auto Visão em duas partes: a primeira, define as condições e garantias para o trabalhador VW; a segunda, cria possibilidades no campo do desenvolvimento econômico local, a partir da inserção de estruturas regionais existentes.

De forma sintética, o acordo abrange:

1)as cartas enviadas pela empresa aos 1923 trabalhadores foram canceladas;

2) criação de um Centro de Formação e Estudos -CFE: os trabalhadores poderão se dirigir para o CFE de forma voluntária. Alocados, poderão optar em estudar e se requalificar até o final de sua estabilidade (outubro de 2006). Poderão ainda optar por ficar em casa e receber todos os benefícios até o final do período. Durante estes meses, estarão devidamente afastados de suas atividades profissionais cotidianas;

3)a empresa abriu um processo de voluntariado para todos os trabalhadores interessados na rescisão contratual. Para isso, além de 0,4 salário por ano trabalhado (resultado de acordo anterior), o voluntário ainda receberá um pacote de mais de 20 salários nominais, bem como os demais municípios;

4)o sindicato terá representante no conselho gestor do projeto Auto Visão Brasil;

toda a discussão que envolve a constituição de novos negócios em prol do desenvolvimento econômico local será pautada no interior da Agência de Desenvolvimento Econômico do Grande $A B C$.

(Extraído de DIEESE - S.Bernardo, São Paulo, Sobre a Auto Visão, 5/12/2003).

A forma como o projeto foi anunciado ou desenvolvido na Alemanha indicou uma possibilidade concreta de desenvolvimento regional, com recursos vindos da empresa e a participação sindical. Essa característica - de se interessar e participar do debate sobre alternativas econômicas 
para a região - que foi desenvolvida pelo sindicato dos metalúrgicos no contexto da crise econômica do ABC nos anos 1990 (cf. RODRIGUES; RAMALHO, 2007; LEITE, 2003; BRESCIANI, 2004; DANIEL, 2001), encontrou na proposta da Auto Visão Brasil uma possível oportunidade para implementar novas soluções.

A Auto Visão não é uma empresa, é um projeto no qual você terá um conselho. Esse conselho terá participação do sindicato. Está assegurado no nosso acordo, terá participação da Volkswagen, possivelmente terá a participação da comunidade, das prefeituras. Se dedicará ao seguinte: atuar no desenvolvimento de projetos. (...)Então a Auto Visão, eu diria que é um espaço de consultoria e análise de projetos e de apoio para o seu desenvolvimento, utilizando as capacidades da própria Volkswagen ou da região. (...)A Volkswagen certamente entra com parte dos recursos, mas a comunidade também tem que entrar. (...)Há uma série de coisas..., um empreendimento turístico não é um empreendimento da Volkswagen, ela pode entrar como parceira, por exemplo franqueando a fábrica para as visitas, aportando uma parte dos recursos para em conjunto com outros setores construir o museu do automóvel. (José Lopes Feijóo, Presidente do Sindicato dos Metalúrgicos do $A B C$, em 18/06/2004, São Bernardo, SP).

Todas essas questões trazem à tona o debate sobre "responsabilidade social das empresas", em especial das empresas multinacionais. Entidades brasileiras de defesa dos trabalhadores já vêm discutindo essa temática há algum tempo e têm ressaltado a importância de incluí-la na pauta sindical. No trecho a seguir, parte da publicação Observatório Social em Revista (2003), pode-se observar um exemplo dessa preocupação, através das palavras de Luiz Marinho, à época presidente da CUT.

O caso Volks é um bom exemplo da diferença entre o discurso e a prática da responsabilidade social, entre o que se diz e o que realmente se faz. Marinho acredita na legitimidade da discussão sobre responsabilidade social entre os sindicalistas: "Apesar do entendimento de que a respon- 
sabilidade social das empresas não passa de política compensatória, acredito que os sindicatos devam envolver-se com o assunto. Nós não temos o direito de, em nome de um sonho com o qual nos comprometemos, deixar de trabalhar com as políticas que, muitas vezes, podem ajudar muitos trabalhadores a sobreviver. Os sindicatos não podem fechar os olhos para estas políticas e simplesmente acusá-las como vinculadas aos interesses do capital". (Extraído de Observatório Social em Revista - Outubro de 2003, Ano 2, No 4, Pp.36,37).

\section{Conclusão}

As experiências de formulação e de intervenção social contidas no projeto AutoVision da VW contribuem para um debate sobre as diferentes estratégias das empresas estruturadas globalmente no sentido de incorporar princípios de flexibilidade tanto ao discurso quanto à prática fabril. Mas revela também o processo detalhado pelo qual as novas estratégias se configuram para além das relações de trabalho internas às fábricas, envolvendo localidades e poder público.

Algumas constatações podem ser feitas e desafios são postos para a interpretação sociológica a partir desse exemplo:

1) $O$ processo de reestruturação industrial alterou de forma definitiva as estratégias das grandes empresas organizadas globalmente. $\mathrm{O}$ enxugamento das fábricas, a estruturação em rede e a flexibilização das relações de trabalho criaram uma nova situação social dentro e fora do espaço da produção. O exemplo da VW reforça o argumento de que empresas globais utilizam sistematicamente a sua presença em vários países para impor novas condições de trabalho agora flexíveis. Esta mobilidade dos novos investimentos empresariais tem sido utilizada para pressionar mercados de trabalho tradicionalmente regulados e refazer acordos cos- 
turados ao longo de anos de negociação pelos sindicatos. No caso do projeto AutoVision, sua implantação na Alemanha resultou na ruptura de acordos trabalhistas estabelecidos no nível nacional e, no Brasil, apareceu como uma estratégia para esconder o seu verdadeiro objetivo que era amenizar uma situação critica de redução de postos de trabalho criada pela própria $\mathrm{VW}$ no $\mathrm{ABC}$.

2) No caso da VW, a resistência aos princípios da flexibilidade por parte dos sindicatos e das comissões de fábrica variou conforme as tradições e práticas políticas acumuladas em conjunturas anteriores. Se estes princípios formam um conjunto comum aplicável indistintamente às diversas sucursais da empresa no mundo, sua aplicação precisa adaptar-se às condições diversas e às especificidades históricas e institucionais que marcam as regiões e países. O projeto AutoVision é particularmente interessante porque surgiu em um contexto de crise econômica e social da região alemã, mas com uma proposta pró-ativa e de expansão como modelo para outros lugares do planeta; foi constituído para responder às críticas formuladas pelos sindicatos e pela localidade acerca do desempenho da VW no processo de reestruturação, particularmente no que diz respeito ao aumento do desemprego na cidade de Wolfsburg. Chama a atenção nesse contexto, tanto a naturalização do conceito de flexibilidade que aparece no discurso sobre os novos empregos e o caráter de inevitabilidade das práticas às quais o conceito se refere, quanto os impedimentos para a replicação do modelo VW a outras realidades, como a do ABC paulista, por exemplo.

3) Diante da força da crítica social que responsabiliza a empresa pelo desemprego, construída principalmente pelos sindicatos e comissões de fábrica dos dois países, o projeto AutoVision se distingue pela capacidade da empresa em incorporar a crítica e respondê-la através de uma retórica marcada pela positividade e pela proposta de criação de novas oportunidades através de empregos flexíveis. Essa estratégia considerou 
a participação sindical e operária na sua execução, como no exemplo alemão, quando as empresas criadas - Wolfsburg AG e AutoVision GmbH - contaram com a presença sindical no seu planejamento e implantação. Por outro lado, o projeto serviu também para dar uma satisfação às localidades nas quais a empresa se encontra enraizada. O exemplo brasileiro apenas comprova que existem graus diferentes de compromisso da VW com as diferentes localidades e que seu compromisso depende também do poder de pressão moral que as localidades conseguem exercer.

4) O exemplo discutido confirma a importância de se considerar no debate sociológico, as questões que abordam a relação de localidades e regiões com as estratégias das empresas globais. Embora a relação das grandes empresas com as localidades onde estão instaladas não se caracterize necessariamente pela estabilidade e pelo enraizamento, parece inevitável que sua presença estimule a constituição de um certo compromisso moral com o território, assim como a sua atual articulação em rede coloque em foco o encadeamento com pequenas e médias empresas tradicionalmente mais estáveis na sua ligação com as localidades.

5) O projeto AutoVision pode ser visto como um exemplo de estágio mais avançado e sofisticado de implantação dos princípios da flexibilidade, na medida em que transforma estratégias anteriores de imposição de novas relações de trabalho em uma pauta positiva de enfrentamento do problema da redução do emprego. Um dos elementos dessa transformação tem relação direta com uma retórica marcada por argumentos de uma responsabilidade social corporativa, preocupada em buscar novas alternativas de vida e trabalho para as pessoas e regiões. $\mathrm{O}$ discurso da empresa revela a construção de uma justificação às críticas sociais feitas ao seu modelo de produção "enxuto", ao mesmo tempo em que busca elementos de legitimação para as novas estratégias flexíveis implantadas, o que inclui um protagonismo empresarial na formulação de propostas 
para as questões sociais (e ambientais) com vistas a assegurar a reputação em um contexto de insegurança econômica, tanto para trabalhadores como para localidades.

\section{Flexibility and the industrial employment crisis - unions, regions and new business actions}

\section{Abstract}

Flexibility is a key word that summarizes the changes that resulted from the restructuring of the industry in the recent decades. The decrease in industrial employment, as well as its social and economic consequences, is the focus of the social criticism directed at projects based on the flexible pattern, which require more and more actions from the part of the companies to justify and legitimize this new facet of the production process. The AutoVision project of the multinational automobile manufacturer Volkswagen - implemented in two regions: Wolfsburg, in Germany, and the ABC Region in the state of São Paulo, Brazil - presents the characteristics of a social intervention that comes with a more elaborate discourse of justification. The hypothesis to be tested is that the latest initiatives of globalized companies based on flexibility point to a political pre-eminence in the formulation of proposals intended to mitigate the effects of the decrease in industrial employment, and to the construction of a rhetoric that endorses flexible employment. Theoretically, this case allows the discussion of different social arrangements based on flexibility, which are created by multinational companies, and the ways these companies justify their actions.

Keywords: Flexibility. Productive restructuring. Global companies. Labor relations.

\section{Referências}

ABREU, A.; BEYNON, H.; RAMALHO, J.R. The Dream Factory: VW's Modular System in Resende, Brazil. Work, Employment and Society. UK: Cambridge University Press, v. 14, n. 2, p. 265-282, junho de 2000. 
AUTOVISION GMBH. Disponível em: <http://www.autovision-gmbh.com>, acesso em: 14 de abril de 2005.

BOLTANSKI, L.; CHIAPELLO, E. Le Nouvel Esprit du Capitalisme. Paris: Gallimard, p. 292 e p. 94-95, 1999. 843 p.

BARBOSA, Mário. Entrevista com ex-trabalhador da WW do Brasil, ex-membro do Comitê Mundial da VW, ex-diretor do Sindicato dos Metalúrgicos do ABC e coordenador do curso de Políticas Públicas do sindicato, em 04/06/2004, realizada por Iram Jácome Rodrigues e José Ricardo Ramalho. São Bernardo do Campo, São Paulo.

BRESCIANI, Luís Paulo. Instituições, agenda regional do desenvolvimento econômico e política sindical no Grande ABC: os desafios do equilíbrio entre a (macro) esfera institucional regional e a (micro) esfera cotidiana produtiva. ANPOCS, Caxambu, 2004. 20 p.

BRONCHAIN, Philippe-Ed. Towards a sustainable corporate social responsibility. European Foundation for the Improvement of Living and Working Conditions. Luxembourg: Office for Official Publications of the European Communities, VI, p. 7-14, 2003. 48 p.

CASTELLS, Manuel. A Sociedade em Rede. São Paulo, Paz e Terra, p. 298-299, 1999. $617 \mathrm{p}$.

COOKE, Philip. The local question - revival or survival? In: COOKE, P. (Org.) Localities - the changing face of urban Britain. London, Unwin Hyman, 1989. p. 296.

DANAU, D.; KOUTSIVITOU, A.; TORTOPIDIS, A.; WINTERTON, J. Factors for Success: A Compendium of Social Partner Initiatives relating to the Employment Guidelines of the European Employment Strategy. Brussels: European trade union confederation; Union of industrial and employers' confederations of Europe; European centre of enterprises, 2000.

DANIEL, C. Uma Experiência de Desenvolvimento Econômico Local: A Câmara Regional do Grande ABC. In: GUIMARÃES, N.; MARTIN, S. (Orgs.), Competitividade e Desenvolvimento - Atores e Instituições Locais. São Paulo, Editora Senac, p. 449-469, 2001.

Declaration on Social Rights and Industrial Relationships at Volkswagen. The Group Global Works Council, Volkswagen AG International, Metalworkers' Federation. Bratislava, 6 de Junho de 2002.

DIEESE. S.Bernardo. Sobre a Auto Visão. São Bernardo, São Paulo, 5/12/2003.

DRIBBUSCH, H. Agreements on cost-cutting and job security signed at Volkswagen. EIROnline - European Industrial Relations Observatory On-line, 11, 2004: VI. Dublin, Irlanda. Disponível em: <http://www.eurofound.europa.eu/ eiro>, ID: DE0411203F. 
EIROnline - European Industrial Relations Observatory On-line, 01, 2004: VI. Dublin, Irlanda. Disponível em: <http://www.eurofound.europa.eu/eiro>.

FEIJÓO, José Lopes. Entrevista com o Presidente do Sindicato dos Metalúrgicos do $A B C$, realizada por Iram Jácome Rodrigues e José Ricardo Ramalho em 18/06/2004. São Bernardo, São Paulo.

HAIPETER, T. Mitbestimmung bei Volkswagen. Neue Chancen für die betriebliche Interessenvertretung? Münster: Westfälisches Dampfboot, 2000.

HARTZ, P. Job Revolution: wie wir neue arbeitsplätze gewinnen können. Frankfurt: Frankfurter Allgemeine Buch, 2001. (Tradução de Mario Barbosa).

IG Metall . Trade Union between tradition and modern times. Alemanha, IG Metall, 2004.

JÜRGENS, Ulrich; KRZYWDZINSKI, Martin; TEIPEN, Christina. Changing Work and Employment Relations in German Industries - Breaking Away from the German Model? Discussion Paper SP III 2006-302. Berlin, Wissenschaftszentrum Berlin für Sozialforschung, p. 3-28, 2006.

. Governance compromises on the employment relationship in Germany - new trends in the automotive, telecom and video games industry. Thirteenth Gerpisa International Colloquium. Paris, Ministère de la Recherche, p. 14-18, 16-17 june 2005.

KAYS, Ditlet; LAVON, Eva. Entrevista realizada com o representante da comissão de fábrica da VW na AutoVision GmbH em 24/04/2007. Salzgitter, Alemanha.

KINDERMAN, Daniel. On the Paradoxes and Ambivalences of Corporate Responsibility in Contemporary Europe. Berlin, Wissenschaftszentrum Berlin für Sozialforschung, p. 2-3, 2007. Mimeo.

LEITE, M. P. Trabalho e Sociedade em Transformação: Mudanças Produtivas e Atores Sociais. São Paulo: Perseu Abramo, 2003.

Observatório Social em Revista - Ano 2, n. 4. p. 36-37, outubro de 2003.

PROMBERGER, M.; ROSDÜCHER, J.; SEIFERT, H. Beschäftigungssicherung durchArbeitszeitverkürzung. 4-Tage-Woche bei VW und Freischichten im Bergbau, Berlin: Edition Sigma, 1996.

RAMALHO, J.R.; SANTANA, M. S. Trabalho e Desenvolvimento Regional - efeitos sociais da indústria automobilística do Rio de Janeiro. Rio de Janeiro: Editora Mauad, 2006. 239 p.

Relatório Anual da WW AG 2002. From employee to co-operator - Auto 5000 $\mathrm{GmbH}$ and the future of industrial labour in Germany. Wolfsburg: Volkswagen AG, 2002. 
Relatório sobre Sustentabilidade 2005/2006. VW AG - Moving Generations. Wolfsburg: Volkswagen AG, p. 4-43, 2006.

Relatório Anual da Volkswagen AG. We want to move forward setting a good example. Wolfsburg: Volkswagen AG, p. 13-15, 2002.

Relatório da Volkswagen AG 2006. One plus one equals three - Corporate Social Responsibility at Volkswagen. Wolfsburg: Volkswagen AG, 2006.

RODRIGUES, I.J.; RAMALHO, J.R. Trabalho e sindicato em antigos e novos territórios produtivos - comparações entre o $A B C$ paulista e o Sul Fluminense. São Paulo: Annablume, 2007. 364 p.

SCHEELE, A. Volkswagen presents plan for 5,000 new jobs. EIROnline - European Industrial Relations Observatory On-line, 03, 2000. Disponível em: < http:// www.eurofound.europa.eu/eiro $>$. Institute for Economic and Social Research, WSI, 2000.

SCHNARE, Heide. Secretária política da IG Metall Wolfsburg encarregada do projeto AutoVision e da comissão de empresa da AutoVision GmbH. Entrevista realizada em 23/04/2007.

SCHULTEN, Thorsten. Agreements signed on Volkswagen's '5000 x 5000' project. EIROnline - European Industrial Relations Observatory On-line, 09, 2001. Dublin, Irlanda. Disponível em: <http://www.eurofound.europa.eu/eiro >. ID: DE0109201F.

. Volkswagen sets up a world group council. EIROnline - European Industrial Relations Observatory On-line, 06, 1998. Dublin, Irlanda. Disponível em: <http://www.eurofound.europa.eu/eiro >.

SCHUMANN, Michael; KUHLMANN, Martin; SANDERS, Frauke; SPERLING, Hans Joachim. Anti-tayloristic model of factory organization - Auto 5000 at Volkswagen. La Lettre du Gerpisa, n. 182, feb./mar. 2005. (Soziologisches Forschungsinstitut SOFI Göttingen). Paris, GERPISA.

SILVA, Cleide; SCHNEIDER, Ari. A Volks não pode nem pensar em sair do País - entrevista com Paul Fleming, presidente da VW-Brasil - Jornal O Estado de S. Paulo, 10 de agosto de 2003.

Volkswagen Communications. Historical Notes - A series of publications from the Volkswagen Communications. Wolfsburg: Corporate Archives Wolfsburg, 2001.

Wolfsburg AG - A vision with definite prospects. Disponível em: < http://www. wolfsburg-ag.com>. Acesso em abril de 2007.

Recebido: 08/10/2008

Aceite final: 04/11/2008 
